\title{
'Superheroes know where they are going': views from children's cultural worlds
}

\author{
Frances Clerkin
}

School of Education, UCC

Imagination is more important than knowledge. For knowledge is limited to all we now know and understand, while imagination embraces the entire world, and all there ever will be to know and understand. (Albert Einstein)

\section{A 'world' of difference}

Eileen asks 'why does Liam need a compass?', an item which Liam proudly produces from his backpack and displays at morning 'show and tell'. Liam often leads play episodes and is frequently an instigator of 'superhero' type play in pre-school. My response is 'he probably needs it for his superhero game'. Eileen's exasperated reply is 'superheroes know where they are going'. On quick reflection I agree that 'yes, that sounds likely.' In her initial statement, Eileen reveals not only that she knows the purpose of a compass but also that she expects a more considered and believable answer from a 'knowing other.' In Eileen's social and cultural experiences, my being adult confers just such a status. Clearly disappointed with my response she herself assumes an 'expert' role. Eileen reflects a shared understanding of culturally embedded assumptions associated with fictional Superhero characters. She also conveys a sophisticated awareness of the 'rules' of pretend worlds, an awareness that suggests that, even where disbelief is suspended, such 'realities' infer rules of engagement, perhaps open to negotiation but rules nonetheless.

The above scenario highlights that children come to pre-school having already absorbed a multitude of messages from the outside world out of which they try to make and share sense. Children's play realities arguably represent cultural 'worlds' within 'worlds', where they interpret, share and negotiate understandings, reflecting influences from media, computer technology, books, toys, pre-school and other social and cultural sources on their lives. It transpires that, on this occasion, Liam's intended use of the compass is as an explorer, replete with handmade map and compass to pursue hidden treasure, at a leisurely as opposed to "superhero in pursuit of 'bad guys"' pace. 


\section{Socio-culturalism, a multi-lensed camera}

This socio-cultural take on children and childhood highlights relational and situated aspects of learning and development. In this qualitative research approach, I enter a preschool community as a volunteer, seeking an increasing participation level in a situated community of practices. Through my participative role/s I seek to observe and record insider child and adult perspectives. Every participant, including myself as 'participant observer', brings their own historic, social and cultural experiences and agendas to bear on the research context, the inference being that any single context represents multiple realities or 'worlds' within 'worlds' which are constantly evolving. This approach challenges assumptions of objectivity which privilege researchers as 'experts' separated from the context of the research. It also acknowledges the imbalance of power between adults and children and pays particular attention to accessing and reflecting children's cultural perspectives.

This study reflects new sociological views on 'children' and 'childhood' that deny the notion of 'universal childhood' or a 'universal child'. Childhood 'culture' is viewed contextually within communities of practice. This research process explores what possible ways of being, seeing and doing are available and appropriated by children within everyday situated pre-school contexts. It also considers associated concepts of children as experts in their own cultural worlds, particularly in relation to their interactions in self initiated play experiences. Such times, often at the interstices of adult control are viewed as significant because of their potential for children to be self-directed and autonomous. This line of research recognises childhood as a valuable time in its own right and runs counter to perspectives that define children as 'incomplete' future adults, with adulthood viewed as the pinnacle of development. It has been argued that such views foreground children as primarily powerless and in need of protection. The counter-argument recognises childhood as a time in life that can never be repeated (OECD 2006). Out of this view of early learning and development are theorised opportunities for reciprocity and co- construction of meaning and shared learning in adult-child interactions

\section{Methodology}

The method adopted seeks invitations from children to participate, to in a sense go 'through the looking glass' and experience what these 'worlds' within 'worlds' might look and feel like from the perspectives of the child participants. Physical body positioning is important in this respect. When seated on the floor or a low chair, there is direct eye contact with children and a potential to engage invitations to participate. Unlike Alice's experiences of being lost in 'wonderland', it is proposed that a 'doorway' with the possibility to enter on invitation but also exit when met with the demands of other roles may be possible. 
As well as this participatory approach, children's language and tool usage is explored and interpreted.

The scarlet cape is one such cultural tool in this setting that evokes many possible functions in the children's play roles from 'Kings' and 'Queens' to 'Superheroes'. The predominantly male perception of the superhero type role as reproduced by the children seems to limit its attractiveness as a play role for girls in the setting. However, this is not always the case. Marian creatively combines two roles and wears the cape over a Disney princess gown to transform herself into a 'Superhero Princess'. She further challenges gender boundaries by transforming herself into a 'Superhero King' when she adds a handmade crown to her ensemble and leads play episodes in new directions. As the transition from indoors to outdoors occurs, Rory picks up the sides of his raincoat, thunders past me saying 'don't close it... I must fly'. I am struck by the fluidity of identity in children's play interactions. They try on identities and explore new ways to be, see and do. Through these interactions they develop cognitive, social and emotional shared understandings that serve to extend and sustain their play themes.

During outdoor play, a doorway into the superhero world opens as Liam offers me a 'magic crystal' (a stone) to help me 'fly'. This exciting opportunity is pursued for several minutes as the more experienced superheroes fly with capes (hoods on head and the body of the coats held out to enable 'flight'). Children's imaginative use of symbols in play, supported by the tools of language, helped them to transcend the limits of their material resources. Suddenly, a heated physical battle erupts between two superheroes and I morph back into my adult role to mediate the dispute. A limitation of this approach means that for now the participatory 'door' into children's play cultures has closed. As in other research studies, some children persistently resist adult efforts at play entry and this is respected. However, many children seem to enjoy guiding my participation in their unfolding play themes and I continue to avail of such invitations.

\section{Creators and meaning makers}

The big underlying concept of this study is the notion of children as active agents, constantly interpreting, making meaning, improvising, being creative, constructing, deconstructing and reconstructing their worlds and making their culture in the moment. The exploratory nature of the study seeks new means to enter or be invited into what is perceived as children's play and learning worlds. It aims to envisage what matters to children, as well as what learning they are reflecting back, interpreting or transforming in play and what emergent themes motivate their dispositional interests that may develop along lifelong learning trajectories. Adopting a least-adult/novice as opposed to adult/expert role requires the researcher to follow where the child's play intentions may lead. This is not to say that there is ever direct access into children's minds. Rather, the hope is that children 
might invite us to momentarily shed the power within adult roles. This opens the possibility of better understanding and co-constructing understandings on what motivates, interests, constrains or enables children within the situated contexts of their unfolding learner identities.

This study links to growing understandings from neuroscience, psychology and sociology on the dynamics of early learning and development. These new understandings suggest the human capacity from infancy to develop creative, cognitive and emotional intelligence through playful social interactions in stimulating environments. My findings affirm the special mediating role of informed and reflective professionals in preserving and extending children's play and learning worlds. My study builds on socio-cultural theory and indicates that such professional practice may usefully incorporate both novice/learner and adult/expert roles. The associated practice-based research approach can inform and enhance generative curricular practices, bridging new connections between home and school and adult and child cultures. Accordingly, I argue for policy and practices that raise the professional status of early years educators. This implies supporting their ongoing training in and development of such practice-based research to be shared within and across early learning communities. Acknowledging children as holders of rights and experts in their own cultures implies accessing and supporting their ongoing input and influence. Such influences can and in notable instances (such as Reggio Emilia Schools in Italy) have been applied to the emergent curricula, architecture, layout, design and resourcing of adaptable and sustainable early learning environments.

The themes of flight and fluid learner identities emerging from this research context are representative of the creative, joyful 'what if?' possibilities within children's play and learning experiences. My own guided 'flights' into children's cultural worlds meant unshackling (at least for a while) the acquired layers of adult power and control, to follow and better understand where children's imaginative potential may lead.

Thanks to my supervisors Professor Kathy Hall and Dr Anna Ridgway 